Ersch. in: Der ganze Mensch: Anthropologie und Literatur im 18. Jahrhundert ;

DFG-Symposion, Wolfenbüttel, 1992 / hrsg. von Hans-Jürgen Schings. - Stuttgart : Metzler,

1994. - S. 605-628. - (Germanistische Symposien-Berichtsbände ; 15). - ISBN 3-476-00997-1

\section{Alphabetisation und Empfindsamkeit}

Albrecht Koschorke (München)

Bekanntlich bringt die Aufklärung ein umfassendes Alphabetisationsprogramm mit sich. Vor allem in der zweiten Hälfte des 18. Jahrhunderts kommt es zu einer breiten Verschriftlichung von Kommunikation.' Schreiben, zuvor eine auf bestimmte Professionen eingeschränkte und weitgehend von Spezialisten ausgeübte Tätigkeit, wird in den Trägerschichten der aufgeklärten Kultur erstmals ein Alltagsphänomen. Über den gewachsenen technischen Bedarf an schriftlichen Informationen hinaus zeigt sich das an dem habituell werdenden Privatgebrauch von Schrift, sei es in der Form des Tagebuchs und anderer Buchführungsarten, sei es im anschwellenden Briefverkehr. Das Gleiche gilt für den Umgang mit gedruckten Werken. Verbesserungen des Postwesens, Ausbreitung und Kapitalisierung des Buchmarktes bilden dafür die materiellen Grundlagen. Von »Lesewuth« und »Autorsucht« ist in den zahlreichen zeitgenössischen Polemiken die Rede, die eine explosionsartige Verbreitung des Schriftgebrauchs diagnostizieren und darin eine Bedrohung hergebrachter familialer und gesellschaftlicher Strukturen sehen.

Schriftlichkeit hört auf, sich an Privilegien zu knüpfen. Den Musterfall eines privilegierenden Umgangs mit Schrift bildete das alte Christentum: im Zentrum des Glaubens das Buch schlechthin, die Bibel, konzentrisch angeordnet um diese Mitte eine Hierarchie von Interpreten, während die Vermittlung an das Volk durch Prediger erfolgte, also in mündlicher Form. Die durch den Buchdruck bedingte zunehmende Lektüre von Glaubensschriften seit der Reformation, das Zurückdrängen des den Gelehrten vorbehaltenen Lateins, schließlich der Übergang vom Erbauungsschrifttum zur schönen Literatur, für den in Deutschland Namen wie Gellert oder Klopstock stehen, geht kommuni-

1 »Was vor allen Details und Einzeltrends aufalle, ist die sprunghaft wachsende Verschriftlichung der Kommunikation.« (Nikolaus Wegmann: Diskurse der Empfindsamkeit. Zur Geschichte eines Gefühls in der Literatur des 18. Jahrhunderts. Stuttgart 1988. S. 15) - Zu den Schwierigkeiten der statistischen Verifikation solcher Prozesse bei Bestätigung der allgemeinen Tendenz: Ernst Hinrichs: Einfuhrung in die Geschichte der Frühen Neuzeit. München 1980. S. 100 ff. 
kationshistorisch mit einem kontinuierlichen Rückzug der oralen Zwischeninstanzen zwischen Buch und Rezipient, mit einer Dezentralisierung des Buch wissens einher. Dieser Vorgang betrifft nicht nur den religiösen Bereich. Auch in der Literatur löst sich Schriftlichkeit aus ihrer Einbettung in mündliche Interaktionen. Sie entzieht sich dem Paradigma der Rede, das, kodifiziert in der alteuropäischen Universalwissenschaft der Rhetorik, sprachliche Außerungen grundsätzlich an Adressaten und Situationen band und damit eine kommunikative Praxis repräsentierte, die ihre Gültigkeit mit der Durchsetzung typographischer Reproduktionsformen schrittweise verlor. ${ }^{2}$ Während die klassische Rhetorik das Schreiben als inferiores Hilfsmittel behandelt hatte, tritt die Schrift nun in wachsendem Maß in Konkurrenz zur Rede und prägt ihr die eigenen Strukturen auf. Literale Kommunikation - um diesen langwierigen ProzeB schlagwortartig abzukürzen - verhält sich zur mündlichen Interaktion nicht mehr subsidiär, sondern substitutiv.

Das bringt auch auf der Rezipientenseite neue Habitualisierungen hervor. Wie einer Studie Erich Schöns zu entnehmen ist, drängt stumme individuelle Buchlekture mit immobilisiertem Körper, dem Modell gelehrter Disziplinierung nachempfunden, in wachsendem $\mathrm{Maß}$ den lauten Vortrag und die daran geknüpften, in der Tradition der Rhetorik verankerten kollektiven Rezeptionen zurüick. ${ }^{3}$ Die Etablierung dieses Lesetyps verbindet sich mit der Abkehr vom alten Öffentlichkeitsmodell und der Entstehung privater Lebensräume. Insofern enthält die vordringende Literalität tatsächlich, so wie es die Lesesucht-Kritiker befürchten, ein die alten Sozialstrukturen gefährdendes Element: sie setzt korporative Gruppenbindungen und Konsenszwänge außer Kraft und gibt Potentiale der Individualisierung frei, die sich nicht in den herkömmlichen sozialen Umgang integrieren lassen.

Ausbildung von Innerlichkeit stellt sich insofern als Begleitphänomen des Alphabetisationsprozesses dar. ${ }^{4}$ In einer oralen, selbst in einer schriftgestiitzten

2 Hierzu nenerdings: Gisbert Ter-Nedden, Das Ende der Rhetorik und der Aufstieg der Publizistik. Ein Beitrag zur Mediengeschichte der Aufklärung. In: Hans-Georg Soeffner (Hg.): Kultur und Alltag. Göttingen 1988 (= Soziale Welt. Sonderband 6). S. $171-190$

3 Vgl. Erich Schön: Der Verlust der Sinnlichkeit oder Die Verwandlungen des Lesers. Mentalitätswandel um 1800. Stuttgart 1987. S. $63 \mathrm{ff}$.

4 Vgl. Schön, $99 \mathrm{ff}$. »Mit dem Verzicht auf das laute Lesen wird das Lesen von außen nach innen genommen. Und damit trägt es seinen Teil dazu bei, dieses $>$ Innen<, wie wir es uns heute vorstellen, überhaupt erst zu bilden, « (ebd., 114) - Stone findet mit Bezug auf die Entwicklung in England Ansätze dazu schon im 17. Jahrhundert vor: $\gg$ At the same time, there developed a series of almost wholly new genres of writing, the intimately self-revelatory diary, the autobiography and the love letter. [...] these products were the result of a shift from an oral to a written culture among the laity. Literacy is probably a necessary precondition for the growth of introspection. (Lawrence Stone: The Family, Sex and Mariage in England 1500-1800. London 1977 S. 226) - Zum Zusammenhang zwischen Literarisierung und Individualisierung im späten 18. Jahrhundert vgl. Georg Jäger: Freundschaft, Liebe und Literatur von der Empfindsamkeit bis zur Romantik: Produktion, Kommunikation und Vergesellschaftung von Individualität durch »kommunikative Muster ästhetisch vermittelter Identifikation $\lll$. In: SPIEL 9 (1990), Heft 1, S. 69-87. thetorischen Kultur ist der Satz »Ich bin einsam《 streng genommen nicht sagbar, weil er die Gegenwart eines Adressaten, die er leugnet, zugleich voraussetzt. Innerlichkeit hat hier keinen diskursiven Ort, weil es eben für die Abgewandtheit des Individuums von den Interaktionen, die sein Leben bestimmen, kein Medium gibt. Erst Schriftlichkeit in ihrer reinen Form gestattet es, NichtKommunikation zu kommunizieren, und legt damit den Boden für fundamentale Paradoxien der Dichtung seit der Mitte des 18. Jahrhunderts: sei es auktorial in bezug auf die Idee des solitär und kontextlos produzierenden Genies, sei es thematisch im Hinblick auf empfindsame Seelenschwärmerei und romantische Liebe, die als grundsätzlich einsame, weltabgewandte Gefühle mitgeteilt werden.

Der Alphabetisationsschub, der zumal die empfindsame Generation prägt, und die im exzessiven Schriftverkehr jener Zeit crörterten Fragen der Affektmodellierung scheinen also in einer engen Bezichung zueinander zu stehen. Sie sind auf eine gemeinsame Ursache zurtickführbar: nämlich die wachsende gesellschaftliche Interdependenz, die das alte körperdominierte Beziehungsgefüge zwischen den Individuen und die entsprechenden kognatischen und korporativen Strukturen auflöst und in ein komplexes System vielstufiger Distanz. kommunikationen transformiert.

Jede Gesellschaft, so ließe sich verallgemeinernd sagen, erzeugt im Netzwerk ihrer Kommunikationen eine bestimmte Menge an >Abwesenheik. Je vielstufiger die kommunikativen Prozesse werden, desto höher ist ihr Abstrak tionsgrad, ihr Anteil an virtuellen Abwesenheiten. Im gleichen Maß müssen sowohl auf medialer als auch auf psychologischer Ebene neue Integrations möglichkeiten bereitgestellt werden. Die wichtigste traditionelle Technologie, Abwesenheit kommunikabel zu halten, ist die Schrift. Um die Verschriftlichung durchzusetzen, bedarf es aber einer neuen affektiven Instrumentie rung. Mit der Ausdehnung gesellschaftlicher Interdependenz geht auf der Subjektseite ein Anpassungszwang zu einer entsprechenden Steigerung psychischer Mobilität einher. Die affektiven Besetzungen müssen über immer längere Vermittlungsketten immer größere Distanzen bewältigen. Sie müssen sich räumlich wie zeitlich an etwas adaptieren, was mit einem Begriff von Norbert Elias als »Langsicht« zu bezeichnen wäre. Infolgedessen werden sie aus dem Bereich der nahen Interaktionen, also der im wesentlichen oralen und physischen Kontakte zwischen Sippengenossen oder Mitgliedern der gleichen Produktionsgemeinschaft in einer vorindustriellen Ökonomie, abgezogen und heften sich an die weitläufigen Vermittlungen des Netzes der Distanzbeziehungen an. ${ }^{5}$

Die Ausdehnung ihrer mentalen Reichweite wird mit der Schwächung ihrer Gegenwartsbezogenheit erkauft. Die Lustbesetzungen strukturieren sich um; in stärkerem Maß als zuvox gehen nun Lust und Entfernung eine Art von Symbiose ein. Die Affekte, die sich den neuen Verkehrsformen adaptieren, gewin-

5 Vol. Karl-Heinz Osterloh: Die Entstehung der westlichen Industriegesellschaft und die Revolution der Interaktionsweisen. Europäischer Kulturwandel als psychosoziales Problem. In: Archiv für Kulturgeschichte 58 (1976), S. 340--370. 
nen eine flüchtigere, geistigere Konsistenz. Vergeistigung ist dabei nicht in erster Linie durch eine wie auch immer begründete Änderung moralischer Prämissen bedingt, sondern ein Struktureffekt des Kommunikationssystems.

Welche Wirkungen die Erfindung des Buchdrucks in kommunikationstechnischer und kognitiver Hinsicht auf die Gesellschaft der frühen Neuzeit ausübte geht aus Michael Gieseckes ausführlichen Studien zu diesem Thema hervor: Die »Verschriftlichung des Lebens«, deren Anfänge Giesecke nachzeichnet ${ }^{6}$, bildet einen heterogenen Prozeß, aus dem sich bestimmte kritische Zeitpunkte wohl nur unter heuristischem Vorbehalt isolieren lassen. Dennoch spricht vieles dafür, daß er erst in der Aufklärung im Zuge der zunchmenden Intensivie rung des Schriftgebrauchs seine volle lebensweltliche Relevanz entfaltet. Im Verlauf des 18. Jahrhunderts werden zwei Tendenzen deutlich, die sich bei ge nauem Hinsehen wechselseitig bedingen: einerseits die endgültige Durchsetzung einer von literalen Techniken der Wissensverarbeitung und-vermittlung beherschten Kultur, dic sich zumal in den bürgerlichen Sozialisationen widerspiegelt, und andererseits die verstärkte Entwicklung und Veralltäglichung körperenthobener Affekte, wie sie besonders die Literatur der empfindsamen Periode betreibt. Auf eine Formel verkürzt: Empfindsamkeit und bürgerliche Alphabetisation sind zwei Seiten des gleichen Prozesses.

\section{II.}

Johann Heinrich Campes Neues Abeze- und Lesebuch soll die Kinder zum Lesenlernen motivieren. Deshalb wird ihnen unter der Überschrift >Ein Mittel auf hundert Meilen weit mit seinen Freunden zu sprechen< eine Geschichte erzählt. Sie handelt von August und Christel, die »immer sehr gute Freunde waren«. Durch einen Umzug werden die beiden auseinandergerissen. Ihr Trennungsschmerz ist groß, aber der Vater weiß Abhilfe.

"Ihr müsst euch, sagte Augusts Vater, ein Sprachrohr anschaffen, um in der Ferne noch miteinander reden zu können.

Ach, hat man denn ein solches Sprachrohr, riefen Beide, wodurch man hundert Meilen weit sprechen kann?

Bis jetzt noch nicht, antwortete der Vater; aber ihr müsst versuchen, ob ihr nicht selbst eins von der Art erfinden könnt.

August und Christel schlugen die Augen nieder, und fingen von neuen an zu weinen.

Hört, Kinder, sagte darauf der Vater, es bedarf keiner solchen Erfindung; es ist schon längst ein sicheres Mittel bekannt, wodurch ihr abwesend ganz vernchmlich mit einander reden könnt.

Wenn ihr Lust habt, so wollen wir euch das Mittel lehren.

6 Michael Giesecke: Sinnenwandel, Sprachwandel, Kulturwandel. Studien zur Vorgeschichte der Informationsgesellschaft. Frankfurt/M. 1992. S. 73 ff. u. passim. - Ders. : Der Buchdruck in der frühen Neuzeit. Eine historische Fallstudie über die Durchsetzung neuer Informations- und Kommunikationstechnologien. Frankfurt/M. 1991.
O thue es, thue es doch! ricfen die beiden Knaben, indem sie sich schmeichelnd ihm in die Arme hingen.

Ihr habt von diesem Mittel schon gehört, fuhr der Vater fort; es ist die schöne Kunst zu schreiben und zu lesen.

Sobald ihr diese gelernt habt, könnt ihr alle eure Gedanken auf Papier heften, und sie euch einander alle Wochen durch die Post zuschicken.

Dann wisst ihr eben so gut, als wenn ihr euch einander gesprochen hättet, was jeder von euch gedacht hat und wie er sich befindet. $\ll^{7}$

Diese kleine Geschichte erteilt eine doppelte Lehre. Ihr didaktischer Hauptzweck besteht darin, die Alphabetisation, der die Kinder unterzogen werden, als etwas Begehrenswertes hinzustellen. Wer lesen und schreiben kann, kann eine bestimmte Form von Schmerz vermeiden: den Trennungsschmerz. Durch die Ubermittung von auf Papier gehefteten Gedanken, wie Campe hölzern und präzise formuliert, läßt sich das Getrenntsein überwinden. Der zweite Teil der Lehre sagt folglich, daß Freundschaft nicht an Nachbarschaft gebunden ist. Insofern mündlicher Kontakt der Gedankenibbermittlung dient, ist er medial ersetzbar.

Aber Medien sind niemals bloße Substitute. Sie verändern, indem sie zu ersetzen scheinen. Der Eingriff, den sie dabei vornehmen, erfolgt, ohne von den Betroffenen je ganz durchschaut zu werden. Campes Fabel kann hier zum Muster dienen. Sie führt den Schriftverkehr als erweiternde Prothese akustischer Verständigung an. Mit den Mitteln der Mündlichkeit ist das, wie die Kinder schnell begreifen, unmöglich: es gibt kein Sprachrohr, das gesprochene Worte über hundert Meilen trägt. Also muß eine emergente mediale Ebene gefunden werden. Und diese Form, »abwesend ganz vernehmlich mit einander« $\mathrm{zu} \gg r \mathrm{r}$ den «, heißt Schrift. Doch indem das Schreiben scheinbar mühelos in die Funktion des Sprechens rückt, bleibt verschwiegen, was das Medium nicht ersetzt. Campe läßt die Kinder damî zufrieden sein, ihre Freundschaft als Austausch von Gedanken fortzusetzen. Seine Geschichte hat also einen Hintersinn: die Funktion der Alphabetisierung besteht nicht nur darin, intellektuelle Substrate zu übermitteln, sondern auch darin, die Körper, die zuvor die Träger der Ver. bindung waren, zu unterschlagen.

Threr medialen Form nach legt Schriftlichkeit die Körper darauf fest, absent zu sein. Sie aktiviert die Aufteilung des Menschen zwischen Geist und Körper, die in den Zeiten Platons gemeinsam mit der Durchsetzung des Alphabets entstand, indem sie den Körper aus dem Spiel nimmt und den Geist verkehren läßt. Schrift (was auch immer Derrida dazu sagt) funktioniert platonisch.

Die Urszene des Schreibens, wie Campe sie erfindet, entspricht in ihrer kindgemäßen Adaption durchaus dem allgemeinen BewuBtseinsstand der Epoche. Gellerts erstmals 1742 publizierte Abhandlung yom Briefeschreiben, die maßgeblich für die Abkehr von professioneller Briefrhetorik und für die Einfuhrung des Briefes als alläglichen Umgangsmittels ist, nimmt program-

7 Joachim Heinrich Campe: Neues Abeze- und Lesebuch. Braunschweig 1807. Reprint Leipzig 1973. S. $184 \mathrm{f}$ 
matisch die antike Formel auf, daß der Brief ein Gespräch zwischen Abwesenden sei, um sie nur stilbezogen einzuschränken. ${ }^{8}$

Doch die Norm yom Brief als Gespräch, die Gellert reaktiviert und zugunsten einer breiten Privatisierung des Mediums gegen den offiziösen »Kanzleistil« durchsetzt, ist nicht bloß in stilgeschichtlicher Hinsicht relevant. Sie legt auch das imaginative Feld fest, dem fortan alle auf Schrift bezogenen Akte zugehören. Im Gegensatz zur humanistischen Schreibkunst wird es im 18. Jahrhundert zum geltenden literarischen Ideal, Mündlichkeit zu simulieren. Und diese »Mimesis von Mündlichkeit $\ll^{9}$, die Gellert für den Brief fordert und die eine extreme literarische Ausprägung im Invektivstil der Stürmer und Dränger findet, fällt paradoxerweise mit der Verabschiedung des Redeprimats der herkömmlichen Rhetorik zusammen.

Das Phantasma des Gesprächs verdrängt die Praxis der Rede. In dem Maß, in dem die schriftliche Kommunikation sich von der Aufgabe befreit, rhetorische Konversationstechniken zu supplementieren, nimmt sie Züge einer scheinbaren Mündlichkeit an. Es kommt zu einer Art von sekundärer Oralisierung des Schreibens, die sich im übrigen mit einer wachsenden Tendenz zu inszenierten Sentimentalitäten verbindet. Nicht nur heften sich in einem charakteristischen Übergangsprozeß an die durchsetzungsbedürftigen literalen Techniken noch orale Verhaltensfiktionen - Briefe »sprechen«, sie werden »verschlungen «, geküßt und an den Leib gepreßt -, es geht auch kaum ein Schreibakt vor sich, der sich nicht durch alle Vermittlungen hindurch als intime Interaktion mit dem Adressaten verstünde, und kaum eine emphatische Lektüre, die nicht von entsprechenden Phantasien geleitet wäre.

Wie sich das Phantasma des Briefgespräches umsetzt, läßt eine gleichsam als Geleitstiick zu Gellerts Brieflehre von dessen Vertrautem Rabener entworfene Szene sehen: »Ich stelle mir vor, daß Sie neben mir sitzen, und daß ich alles, was ich schreibe, Ihnen mündlich sage. «10 Das Schreiben, das unter dem Primat des Sprechens steht, wird von der notwendigen Selbsttäuschung begleitet, daß der Adressat gegenwärtig sei. Es ist an die Einbildung einer unmöglichen Präsenz gekoppelt. Und das gilt selbst dort, wo die Tatsache der Trennung ak-

$8 \gg$ Das erste, was uns bey einem Briefe einfällt, ist dieses, daß er die Stelle eines Gesprächs vertritt. Dieser Begriff ist vielleicht der sicherste. Ein Brief ist kein ordentliches Gespräch; es wird also in einem Briefe nicht alles erlaubt seyn, was im Umgange erlaubt ist. Aber er vertritt doch die Stelle einer mündlichen Rede, und deswegen muß er sich der Art zu denken und zu reden, die in Gesprächen herrscht, mehr nähern, als einer sorgfältigen und geputzten Schreibart.« (Christian Fürchtegott Gellert: Briefe, nebst einer praktischen Abhandlung von dem guten Geschmacke in Briefen. Leipzig 1751. In: Ders.: Die epistolographischen Schriften. Faksimiledruck nach den Ausgaben von 1742 und 1751. Stuttgart 1971. Dort S. 2f.)

9 Vgl. Robert H. Vellusig: Mimesis von Mündlichkeit. Zum Stilwandel des Briefes im Zeitalter der technischen Reproduzierbarkeit der Schrift. In: Theo Elm und Hans H. Hiebel (Hg.): Medien und Maschinen. Literatur im technischen Zeitalter. Freiburg 1991. S. 70-92.

10 Zit. n. Rainer Brockmeyer: Geschichte des deutschen Briefes von Gottsched bis zum Sturm und Drang. Diss. Münster 1961. S. 55. zentuiert wird, wie sich überhaupt in den Briefwechseln der Zeit die Trauer über das physische Getrenntsein und die Feier einer kompensierenden geistigen Nähe in unterschiedlichen Tonhöhen ohne erkennbaren Widerspruch mischen. »Ich will«, schreibt Klopstock an Maria Sophia Schmidt, die >Fanny< seiner Gedichte, »mich Threr Erlaubniß bedienen, oft, u lange Briefe an Sie zu schreiben. DieB wird zwar eben so seyn, als wenn ich Sie in einem Nebenzimmer wüßte, u durch eine geschloßne Glasthüre Sie anredete, ohne Sie zu sehen, $u$ ohne daß Sie mir antworteten. Aber unterdeß wären Sie doch auf einige Augenblicke in dem Nebenzimmer, $u$ ich redete Sie an. «1 Auch hier ist das Schreiben ein Sprechen, das die Adressatin in unmittelbare Nähe zum Schreibenden rückt; zugleich bleibt die mediale Verschiebung, die das Oxymoron der undurchsichtigen Glastür verbildlicht, gewahrt und läßt, wie intensiv auch die Imagination von Nähe sich ausgestaltet, den idealen und poetischen Charakter der Liebe ungefährdet.

In der Folge solcher imaginierten Unmittelbarkeiten lagert sich an die Akte des Lesens und Schreibens ein tausendfacher Fetischismus an. Denn Schriftlichkeit schaff allein auf Grund ihree medialen Struktur exakt jene Bedingungen, aus denen auf semantischer Ebene die Fetische der Empfindsamkeit hervorgehen: Distanz, die Nähe suggeriert und eine Sprache der Distanzlosigkeit freigibt; Abschneidung des Körpers, die durch ungehinderte Zusammenkunft der Geister abgegolten wird; Abstreifung des Äußerlichen, die es ermöglicht, daß die hüllenlosen Innerlichkeiten ineinanderfließen.

So treibt die Medialisierung eine neue Mythologie der Unmittelbarkeit hervor. Der Name dieser Mythologie ist Empfindsamkeit. Ihr Schauplatz und ihr Übungsfeld sind die empfindsamen Briefwechsel, seien sie biographischer oder fiktionaler Natur, im weiteren Sinn alle Formen des Schriftverkehrs. Strukturanaloge Vorgänge lassen sich auch in anderen Bereichen finden, zum Beispiel in der Geschichte der Theater- und Kunstrezeption: Separierung und Immobilisierung der Körper einerseits, Spiel der Einbildungskraft andererseits, jenes zentralen ästhetischen Vermögens, das im Zeichen des Versprechens steht, das Abgeschnittene auf imaginärer Ebene wiederzuerstatten.

Was Campe am Beispiel der beiden durch die beruflichen Umstände der Väter auseinandergerissenen Freunde illustriert, trifft einen das 18. Jahrhundert prägenden kollektiven Prozeß. Die wachsende gesellschaftliche Mobilität macht veränderte Verkehrsformen nötig. Auf der Ebene der Zeichenkommunikation sind es die Medien, die eine Zwischenträgerrolle zwischen den auseinandergerückten Individuen übernehmen und dabei das Versprechen übermitteln, den Mangel, der durch wachsende soziale Distanz erfahrbar wird, zu supplementieren. Daran knüpft sich ein Wandel der affektiven Kontrolle. Die empfindsamen Briefwechsel bieten in gewisser Weise die Fortsetzung von Campes Geschichte, die von der Alphabetisation der Freundschaft handelt.

11 Friedrich Gottlieb Klopstock: Werke und Briefe. Hist.-krit. Ausgabe. Hg. Horst Gronemeyer u. a. Abteilung Briefe. Berlin New York 1979 ff. Bd. I, S. 146. - Editorische Sonderzeichen wurden der Lesbarkeit halber getilgt. 
Sie suchen nach Möglichkeiten der Wahrheitsfindung, die nicht von Körperzeichen gewährleistet wird, von Vertrauen, das auBerhalb der Reichweite persön. licher Interaktionen besteht, von Nähe, die nicht auf sinnlichem Kontakt beruht.

Empfindsame Literatur wäre demzufolge so etwas wie >mediales Probehandeln< unter den existentiellen Bedingungen der Schriftlichkeit. Was modellbildend besonders die Romanfiguren tun: nämlich in gerührten Regungen ihre Körperlichkeit negieren, entspricht dem, was dem empfindsamen Leser, Prototyp einer neuartigen einsamen und wortlosen Buchrezeption, allein schon durch seine Leserschaft auferlegt ist. Die Romane semantisicren einen medialen Effekt, sie erzählen die psychodramatischen Abläufe dazu. Sie transponieren die neue, an die zunehmende gesellschaftliche Interdependenz und Medialisierung angebundene Affektkultur in die alten Interaktionszonen: die familiären und erotischen Beziehungen, die nun, bei fortschreitender Einschränkung und Entwertung der körpersprachlichen Ausdrucksmittel, zur Verbalisierung drängen und sich dabei in wachsendem Maß an die Artikulationsformen der Schriftkultur, als der semantisch am weitesten entwickelten Stufe der Verbalität, adaptieren.

Alle Schlïsselbegriffe der empfindsamen Periode - Tugend, Seelenfuille, Sympathie, Zärtlichkeit, Freundschaft -, die sich im Rahmen der neuen bürgerlichen Sozialität entwickeln, werden vorzugsweise in schriftlichen Verkehrsformen, sei es in gedruckter Literatur, sei es mit den Mitteln von Briefwechsel und schriftlicher Introspektion, symbolisch erprobt. Die Schrift ist dabei keineswegs nur Träger yon Inhalten und als Medium neutral; sie unterhält eine enge Komplizenschaft mit der Ideologie von Tügend/Entkörperung/Seele, für die sie das Forum bietet. ${ }^{2}$ Allgemeiner ausgedrückt: Schriftlichkeit ist das kommunikationstechnische Korrelat des diskursiven Phänomens >Seeler.

\section{III}

Alphabetisation hat insofern zunächst privativen Charakter. Sie bildet eine Armatur gegen sinnliche Verführungen aus. Denn das Lesen läßt den Körper latent werden. "Die Seele«, schreibt Hemsterhuis in seinem Brief über das Verlangen,

»ewig in ihrem Wesen und allem Zusammenhang mit dem, was wir Raum und Zeitfolge nennen, ihrer Natur nach zuwicler, bewohnt einen Körper, der sehr verschiedenartig von der Natur der Seele zu sein scheint. Ihre Verbindung mit diesem Körper ist also sehr unvolkommen. Denn in der Zeit, in der Sie diese Zeilen lesen, haben Sie, wenn ich Sie nicht daran erimnere, keine Vorstellung, keine Idee Ihrer Beine, Ihrer Arme

$12 \mathrm{Zu}$ diesem Zusammenhang: Lothar Müller: Herzblut und Maskenspiel. Über die empfindsame Seele, den Briefroman und das Papier. In: Gerd Jüttemann u. a. (Hg.): Die Seele. Thre Geschichte im Abendland. Weinheim 1991. S. 267-290. oder der andern Teile Ihres Körpers. Das Nichtdasein aller dieser Teile wiirde in dem Ich, das in thnen denkt, für den Augenblick durchaus keine Änderung hervorgebracht haben. «33

Lesen ist eine Art von Selbsterfahrung, die die Unzusammengehörigkeit und das Auseinanderstreben von Leib und Seele manifest macht. Der Leser, an dem sich so etwas wie cine temporäre Amputation vollzieht, nähert sich im Akt der Lektüre dem Ideal einer rein intellektuellen Existenzweise an. Seine moralische Aufgabe besteht darin, diesen Zustand der Körperferne zu stabilisieren. Es ist im 18. Jahrhundert ein Gemeinplatz, daß die durch Bücher erwerbbare Bildung bei den Lesern eine gesteigerte Sensibilität, und das heißt Vergeistigung, mit sich bringt. Die Einsamkeit, die für das Lektüreerlebnis grundlegend wird, arbeitet einer feineren Nuanciertheit des Scelenlebens zu und befördert zugleich die Resistenz gegenüber äußeren, sinnlichen Reizen.

Die empfindsamen Helden ebenso wie die Schriftsteller selbst beziehen ihre ganze Seelenkraft aus ihrem Vermögen, sich zum Lesen oder Schreiben zurïckzuziehen und, in der Unveränderlichkeit des geschriebenen Wortes gespiegelt, eine vom flüchtigen Alltagsumgang abgewandte persönliche Identität zu formen. Sophie von LaRoche hat diese Funktion der absondernden Beschäftigung mit Schrift durch einen Handlungszug in der Geschichte des Fräuleins von Sternheim offen dargelegt: die Tante, die das Fräulein fur weitgespannte Hofintrigen gefügig machen und letztlich dem begehrlichen Fürsten ausliefern will, dabei jedoch über deren Tugendhaftigkeit fast verzweifelt, greift zu dem Mittel, die Bücher zu beschlagnahmen, die dem Fräulein eine unangreifbare semantische Privatsphäre sichern. Doch weiß sich die Titelheldin zu helfen, indem sie mit noch größerem Eifer ihr Briefjournal fortsetzt und sich auf diese Weise umso wehrhafter zeigt. ${ }^{44}$ Schon für Richardsons Pamela war das Schreiben selbst, auch ohne die Hoffnung auf einen Adressaten, ein Mittel, der Verführung zu widerstehen. Die Grenze zwischen Tugendhaften und Verführern ist mit der Grenze zwischen denen, die sich durch Bücher bilden, und denen, die sich in zerstrenender Geselligkeit erschöpfen, weitgehend deckungsgleich.

So heftet sich auch eine soziale Opposition an das Alphabetisierungsprogramm. Die bürgerlich-puritanische Verhaltenslehre verdammt die Orte des höfischen Vergnügens und seiner Imitationen, jene Welt der Opern, Bälle, Empfänge, Salons, als Stätten der Prostituierung. Sie untersagt jede ostentative Selbstdarbietung des eigenen Körpers. Während die Hofkultur danach strebt soziale Beziehungen und Konflikte zu personalisieren, werden sie im Berufs bürgertum in zunehmendem Maß über impersonale Mechanismen vermittelt. ${ }^{15}$ Mit den moralischen Umwertungen geht folglich eine Umpolung der kommu

13 François Hemsterhuis: Über das Verlangen. In: Ders. Philosophische Schriften. Hg. Julius HilB. Bd. 1. Karksruhe Leipzig 1912. S. 45-70. Dort S. 54 f.

14 Sophie von La Roche: Geschichte des Fräuleins von Sternhein. Hg. Barbara BeckerCantarino. Stuttgart 1983. S. 79 ff.

15 Norbert Elias: Die höfische Gesellschaft. Untersuchungen zur Soziologie des Königstums und der höfischen Aristokratie. Frankfurt/M. 1983. S. 92, 153 und passim. 
nikativen Strategien einher. Denn das kommunikationstechnische Äquivalent einer durch Geld und Ware vermittelten Sozialität ist die Schrift, wie auch von kulturkritisch inspirierten Schriftstellern herausgestellt wird ${ }^{16}$ In dem gleichen MoralisierungsprozeB, in dem Scham an die Stelle erotischer Reizbarkeit, Rührung an die Stelle sinnlicher Genüsse treten, weicht auch das komplizierte Gefïge der Konversationskultur mit ihren Anforderungen an Körpereinsatz, Geistesgegenwart, Witz und Charme einer alphabetischen Kultur schlichter Häuslichkeit und einsam-asketischer Bildungslektüre.

Im Unterschied zu den Hofleuten und denen, die als ihre bürgerlichen Nachäffer diskreditiert werden, zelebrieren die Empfindsamen bei allen Arten des außerhäuslichen Umgangs, die nicht letztlich schriftbezogen sind, sei es literarisch oder religiös, innerliche Absenz. Sie schätzen die repräsentative Öffentlichkeit nicht, sind allergisch gegen frivole und modische Reize, verachten orale Kontaktformen wie etwa den Klatsch, der sich nun einer Welle von Denunziationen gegenübersieht, und retten sich, wann immer sie können, in die freie Natur - eine Exfahrung, die wie keine andere literarisch induziert ist oder in thre Kammern, um dort durch Brief oder Tagebuch von ihrem gesell schaftlichen Unwillen Zeugnis abzulegen und sich dem stillen Glück der Bücherwelt zu überlassen. Die empfindsame Geselligkeit selbst gründet auf dieser Erfahrung der Abkehr. Wer sich darin übt, mit restringiertem Körper seinen Empfindungen nachzuspüren, ist auch zur Sympathie mit anderen Geistern befähigt. Umgekehrt kann sich von einer sozialen Außendefinition nur emanzipieren, wer Zugang zum semantischen Depot des Inkommunikablen hat: zur empfindsamen Selbstbetrachtung, zur Dichtung. Nur Schrift garantiert die Reserve, die die Empfindsamen als Gemeinschaft Abwesender miteinander verbindet, nur die Ankopplung an den semiotischen Speicher der Schrift erlaubt es, die Erfahrung der Individuation zum kollektiven Lebensgefühl derer aufzuwerten, die draußen stehen. In Abkehr von der weitgehenden Einbindung der Körper in den von Mündlichkeit beherrschten Geselligkeitsformen entstehen inkommunikable Innerlichkeiten, sich selbst ausspiegelnde Höhlungen, die mit den Mitteln direkter Interaktion nicht mehr erreichbar sind und sich allein schriftlich (in einem Zeichensystem, das Absenz darstellen kann) artikulieren. Nicht umsonst besteht die Lieblingsbeschäftigung empfindsam Liebender gerade in der Lektüre und Nachahmung von empfindsamen Liebesgeschichten, das heißt in der symbolischen Inszenierung von Körperferne. ${ }^{17}$

Zumal die Abstinenz vom Tanz als einem erotischen Vergnügen entwickelt sich zu einem stereotypen empfindsamen Gruppensignal, das bis zu Bettine von Amims schriftlicher Goethe-Liebe und in die Texte der Romantiker fort-

16 Am entschiedensten vielleicht bei Adam Müller: Zwölf Reden über die Beredsamkeit und deren Verfall in Deutschland (1812), Dritte Rede.

$17 \mathrm{Vgl}$. hierzu und zu den erotischen Implikationen des Lesens im 18. Jahrhundert allgemein: Friedrich A. Kittler: Autorschaft und Liebe. In: Ders. (Hg.): Austreibung des Geistes aus den Geisteswissenschaften. Programme des Poststrukturalismus. Paderborn u. a. 1980 . S. $142-173$ wirkt. ${ }^{18}$ Und weil bürgerliche Affekmodellierung in der Regel am Modell der Frau ansetzt, wird in immer neuen Varianten der Charakterkontrast zwischen Tänzerin und Leserin ausgeführt und zementiert.

Bodmer und Breitinger veröffentlichen im Mahler der Sitten die angebliche Zuschrift einer Leserin, die nach eigenem Bekunden »in der Gesellschaft der galantesten Mannspersonen« nur »schlechtes Vergnügen« findet ${ }^{19}$, sich von den $\gg$ Sachen, auf welche die Reden bey dem Frauenzimmer insgemein fallen, als Kleider, Karten, Nachreden $\ll^{20}$ entfremdet hat und nach anderen kulturellen Übungen auch das Vergnügen der Lektüre des Spectator entdeckt. »Seitdem ich diese Lust von dem Lesen zu kosten angefangen habe, hat die Lust, die ich hiebevor von den harmonischen Tönen der Musik, von cadanzirten Tritten [...] empfangen hatte, bey mir nicht wenig von ihrem Reitze verlohren. Ich fühle, ich höre, und sehe weit mehr liebliches, und in stärckerm Masse, wenn ich in meinem Zuschauer lese. $\ll^{21}$ Und das Psychogramm der idealen Leserin schließt: »Das ist nun mein unschuldiges und vergnügtes Leben. «22

Richtiges Lesen bewirkt nicht nur eine phantasmatische Intensivierung der Reize - selbst Gefühl und Gehör werden nach der Auskunft dieser fingierten Leserin durch Lektüre stärker in Anspruch genommen als durch physische Realität -, sondern es verbindet damit auch den Vorteil, den Geist in eine gleichsam a priori schuldlose Welt zu entführen. Benekens Jahrbuch für die Menschheit von 1788 enthält einen von Leonhard Meister verfaßten Modelldialog, in dem ein Mann namens Karl seine Gattin Louise über angemessenes weibliches Freizeitverhalten ins Bild setzt:

»L. Tanz, Conzert und Kartenspiel füllen doch die müssigen Stunden weit angenehmer aus, als todte Lectüre!

K. Kartenspiel zählt meine Louise gewiß nicht im Ernst dahin. Tanz und Concert? Freylich geben sie Dem, der das liebt, recht sehr viel Vergnügen; aber wer kann und wer darf es oft genießen? Lecture ist nicht nur weit weniger kostbar, weit weniger gefährlich - ihr Genuß ist auch unendlich reiner und freyer: «33

$18 \gg$ So hab' ich Dich geliebt, indem ich dieser inneren Stimme willfahrte, blind war ich und taub für alles, kein Frühlingsfest und kein Winterfest feierte ich mit, auf Deine Bïcher, die ich immer lesen wollte, legte ich den Kopf und schloß mit meinen Armen einen Kreis um sie, und so schlief ich einen süßen Schlaf, während die Geschwister in schönen Kleidern die Bälle besuchten [...].« (Bettine von Arnim: Goethes Briefwechsel mit einem Kinde. Hg. Waldemar Oehlke. Frankfurt/M. 1984. S. 70f.)

19 Johann Jacob Bodmer, Johann Jacob Breitinger: Der Mahler der Sitten. Von neuem übersehen und stark vermehret. 2 Bde. Zürich 1746. Reprint Hildesheim New York 1972. Bd. I, S. 323.

20 Ebd., 324.

21 S. 326.

22 S. $328 \mathrm{f}$.

23 L[eonhard] Meister: Ueber die weibliche Lectiure. In: Friedrich Burchard Beneken (Hg.): Jahrbuch für die Menschheit oder Beyträge zur Beförderung häuslicher Erziehung, häuslicher Glückseligkeit und praktischer Menschenkenntniß. Bd. 2. Hannover 1788 . S. 35-50. Dort S. 38 . 
Für die Frau, die noch zivilisatorischer Formung bedarf, ist Bücherlesen, abge leitet von der Metapher der >toten Buchstaben<, »todte Lectüre«. Verglichen mit den Mädchen, die tanzen gehen, stirbt die Lesende Abend für Abend einen kleinen alphabetischen Tod. Der Mann widerspricht ihr darin eigentlich nicht, aber er belehrt sie, die Annullicrung des Körpers durch Lektüre von einer anderen Seite zu sehen: ihr Genuß ist $[. .$.$] unendlich reiner und frey-$ er«. Der Tod des Buchstabens ist nur der Durchgang zu einer spirituellen, me dial verwalteten Welt.

IV.

Auf den Tod des Buchstaben folgt die Auferstehung des Geistes. »[...] Ihre Abwesenheit von uns«, schreibt Bodmer 1747 an Sulzer, »und unsere von Ihnen, wäre nicht besser, als der bittere Tod, wenn wir nicht in den Briefen auferstünden und lebten ${ }^{24}$ Es wurde oben schon angedeutet, wie die klassischen Briefleser des 18. Jahrhunderts die Formel vom Brief als Gespräch in ein Ensemble von Phantasmen ïbersetzten. Auf den ersten Blick kann man das metonymische Eintreten der Schrift für den Schreiber in dem konventionellen Sinn verstehen, daß das Schriftzeugnis eine wenn auch unzureichende Entschädigung für die Absenz seines Urhebers bietet. In der zeitgenössischen Brieftopik sind solche Unvollkommenheitsbekundungen durchaus geläufig; nähme man sie beim Wort, so schiene der neue literarische Verkehr im wesentlichen aus einem weitreichenden Ressentiment gegen die Schriftlichkeit selbst zu bestehen. Aber das Substitut Schrift beschränkt sich nicht auf diese dienstbare Rolle. Es bindet fetischistische Energien an sich, die wie jeder Fetisch nicht mehr auf das, was sie ersetzen, zurückführbar sind. Die mediale Gegenwart entwickelt ihre eigenen Valenzen und Intensitäten. "Ich erhielt Deinen Brief«, schreibt St. Preux an Julie in Rousseaus Nouvelle Hélö̈se, einem der epochemachenden Muster brieflicher Liebe, "mit der gleichen Entzückung, mit der mich Deine Anwesenheit erregt hätte; und im Ungestüme meiner Freude war mir ein bloßes Blatt Papier Ersatz für Dich «.25 Und wenig später:

»Doch wic sollte man Dich nicht kennenlernen, wenn man Deine Briefe liest? Wie sollte man sich zu einem so rührenden Tone, zu so zärtlichen Gefühlen eine andere Gestalt hinzudenken als die Deinige? Sieht man nicht bei jedem Satz den sanften. Blick Deiner Augen? Hört man nicht bei jedem Wort Deine reizende Stimme? Welche andre als Julie hat jemals so wie sie geliebt, gedacht, geredet, gehandelt, geschrieben? Wundre Dich also nicht, wenn Deine Briefe, die Dich so deutlich zeigen, zuweilen auf Deinen Dich anbetenden Geliebten die gleiche Wirkung als selbst Deine Gegenwart ausüben! Wenn ich sie wieder und wieder lese, verliere ich den Verstand, meine Ge-

24 Wilhelm Körte (Hg.): Briefe der Schweizer Bodmer, Sulzer, Geßner. Aus Gleims litterarischem Nachlasse. Zürich 1804. S. $70 \mathrm{f}$. (Brief vom 12. 9. 1747.)

25 Jean Jacques Rousseau: Julie oder Die neue Héloïse. München 1988. S. 246. danken verirren sich in fortdauendem Taumel, verzehrendes Feuer durchdringt mich mein Blut gerät in Wallung und schäumt, eine wilde Glut läBt mich zittern. Ich glaube, Dich vor mir zu sehen, Dich zu berühren, Dich an meine Brust zu drücken - anbetungswürdiges Wesen! Bezauberndes Mädchen! Quelle von Entzücken und Wollust! Wie kann ich, wenn ich Dich erblicke, nicht die für die Seligen geschaffnen Huris sehen? 2 ?

Körperliche Entfernung ist hier durchaus nicht nur als Mangel begriffen. Vor den Augen der Einbildungskraft entsteht das real Entzogene neu und in nicht minderer Stärke. In seinen autobiographischen Texten wird Rousseau den Eigenwert imaginärer Erfahrungen verteidigen und damit das Paradox einer Unersetzbarkeit des Ersatzes berühren. ${ }^{27}$ So materialisiert die Schrift eine Trennung, die sich in den metaphorischen Nebenhandlungen, die ihren Gebrauch begleiten, fortwährend zu verflüchtigen scheint. Nicht instrumentell, sondern nach dem alten Topos des Seelenspiegels ${ }^{28}$ als physiognomisches Ausdrucksmittel verstanden, läßt die Schrift Stimme, Bild, Gestalt, Körper der Geliebten wiedererstehen: ein fast identisches Doppel, nur eben um die Tatsache dieser Verdopplung vom Urbild entfernt.

Durch das >Fenster der Schriftlichkeit, um Klopstocks Schreibinszenierung aufzunehmen, werden die Personen, so scheint es, nur umso näher aneinandergefiihrt. Die mediale Distanzierung hindert das Begehren nicht, sondern entfacht es; sie läßt es überhaupt zur Sprache gelangen und bietet die Lizenz, Dinge zu sagen oder symbolisch auszuführen, die mit dem Reglement direkter mündlicher Interaktion unvereinbar wären. Die Gefühlswallungen von St. Preux beim Anblick der Zeilen der illegitimen Geliebten sind nur ein Beispiel dafür. ${ }^{29}$ Er kann in verbotenen »Taumel « und »wilde Glut « geraten, die Schreiberin »berühren« und umarmen und doch zugleich in ihr »die für die Seligen geschaffnen Huris sehen«, das heißt die gebotene Distanz in himmlische Entrückung übersetzen.

Immer wieder umspielen die Briefwechsel quälend-lustvoll die Grenze oder den Übergang zwischen Schrift und Körper. »Komm her, mein süßes Mädchen«, schreibt Johann Heinrich Voß an Ernestine Boie, seine Braut, »und sez

26 Ebd., $250 \mathrm{f}$.

27 So in den >Dialogues< im Rückblick auf die ersten Erfahrungen mit Lektüre: »Von seiner Kindheit an hat alles dazu beigetragen, seine Seele von den Orten, die sein Körper bewohnte, loszubinden, um sie in jene ätherischen Gegenden [.. z] zu erheben und dort zu befestigen. « (Rousseau richtet über Jean-Jacques. In: Jean Jacques Rousseau: Schriften. Hg. Henning Ritter: Bd. 2. München Wien 1978. S. 436; vgl. $479 \mathrm{ff}$.)

28 Vgl. Wolfgang G. Müller: Der Brief als Spiegel der Seele. Zur Geschichte eines Topos der Epistolatheorie von der Antike bis zi Samuel Richardson. In: Antike und Abendland 26 (1980), Heft 1, S. 138-157.

29 Eine ähnliche Szene bietet sich, als St. Preux das einem Brief beigelegte Porträt der Geliebten erhält, wie überhaupt der Austausch von Porträts und Schattenrissen ein Analogon zur Fetischisierung des Geschriebenen bildet. Vgl. Rousseau: Julie (Anm. 25), $287 \mathrm{f}$. 
dich auf meinen Schoß; ich will dir ein wenig erzählen. «30 Man kann zumal mî Bezug auf das expandierende Genre der Brautbriefe von einer vollständigen Schoßmystik sprechen. »Was ists, liebste Freundin, das Sie mir auf meinem Schoosse wohl sagen könnten? « heißt eine Stelle in Herders Briefwechsel mit Caroline Flachsland. »Sitzen Sie denn schreibend nicht auf meinem Schoos? Ach, Himmel, Ein Wort aus Ihrem Herzen, ists mir denn nicht eben so, als ob ichs hörte, küßend erhörte? «ㄴ In anderen Briefen vertieft sich das Bild solcher Intimität zu gefühlvollen Infiltrationsphantasien: »Etlauben Sie, daß ich von Zeit zu Zeit mit dem Tagebuch meiner Merkwürdigkeiten fortfahre, und sie der einzigen Freundin in den Schoos schütte, mit der ich gegenwärtig auf der Welt spreche. $\ll^{32}-»$ Laßen Sie mich in Ihren Schoos und kleinen, unschuldigen Busen weinen, meine gute F. $\ll^{33}$

Es wird hier schon erkennbar, daß die mediale Substituierung die Körper in ein anderes Register transferiert. Sie werden zu symbolischen Diskursinstanzen. Wenn Herder vom »kleinen, unschuldigen Busen« seiner Braut spricht, so stellen die beiden Adjektive klar, daß statt des Geschlechtsmerkmals der Sitz der Gefühle gemeint ist, und ähnlich steht die Befeuchtung ihres Schoßes nicht im Zusammenhang mit Sexualsekreten, die im Gegenteil gerade zu dieser Zeit das Ziel einer rigorosen Eindämmung werden, sondern mit den Flüssigkeiten, in denen Empfindsamkeit zirkuliert: Tränen und Tinte. Auch zwischen Männerfreunden spielt diese Metaphorik eine Rolle. »In Deinen Schoß laß mich stille Thränen des harmenden Zweifels weinen«, äuBert sich Lavater an Herder. ${ }^{34}$ Jens Baggesen eröffnet seinen Briefwechsel mit Reinhold mit der Versicherung, daß es ihm ein »wahres Bedürfniß« sei, »Alles, was auf den besseren Theil meines Selbstes bleibenden Eindruck gemacht hat, in den Schoos Threr theilnehmenden Freundschaft auszuschütten $\ll^{35}$, und schildert seine Dankbarkeit über erhaltene Korrespondenz in Bildern femininer Beglïckung: $\mathrm{O}$, mein Reinhold! ich bin in dem Moment des Empfangens jedes Ihrer Briefe nichts als Empfänglichkeit; mein ganzes Wesen wird nicht blos durchströmt, sondern im Strome des seligen Genusses aufgelöst, und Alles, was ich in diesen wonnevollen Augenblicken äußern kann, ist convulsivscher Dank in beinahe tödtender Freude. $\ll^{36}$

In welchem Umfang auch empfindsames Schreiben sich als ein Strömen, Vergießen, Zusammenfließen gebährdet, das mitunter orgiastische Züge an-

30 Johann Heinrich VoB: Brief an Emestine Boie (1774). Erstdruck in: Ernst-Peter Wieckenberg $(\mathrm{Hg}$.$) : Einladung ins 18. Jahrhundert. Ein Almanach aus dem Verlag$ C. H. Beck. München 1988. S. 158.

31 Herders Briefwechsel mit Caroline Flachsland. Hg. Hans Schater. 2 Bde. Weimar 1926/28. Brief vom 17. 8. 1771, Bd. I, S. 287.

32. Ebd., I, 211 (11. 5. 1771)

33 Ebd., 334 (5. 10. 1771).

34 Aus Herders Nachlaß. Hg. Heimich Düntzer und Ferdinand Gottfried v. Herder. 3 Bde. Frankfurt/M. 1856f. Bd. 2, S. 44 (Brief vom 14. 3. 1773).

35 Aus Jens Baggesen's Briefwechsel mit Karl Leonhard Reinhold und Friedrich Heinrich Jacobi. 2 Bde. Leipzig 1831. Bd. 1, S. 1 (Brief vom 10. 12. 1790).

36 Ebd., I, 96 (28. 9. 1791). nimmt, es transportiert spirituelle Substanzen, und die Seelenverschmelzung, die der Briefverkehr induziert, ist kein minderer Ersatz, sondern steht in erklärter Konkurenz zu physischer Interaktion. Die einschlägigen Briefwechsel wären voll von Doppeldeutigkeiten, wenn nicht die Verfasser das Funktionieren der Körper-Seele-Metonymien, die sich an die Schreiber-Schrift-Metonymie heften, als selbstverständlich voraussetzen könnten.

Etwas Ähnliches gilt von den inflationären Symbolhandlungen, die das Herz des Korrespondenten betreffen. Der »innigste [...] Kuß auf Dein Herz«, den Herder seiner Braut übermittelt ${ }^{37}$, würde als galante Liebeseröffnung in handfeste Zärtlichkeiten übergehen oder, wörtlich verstanden, peinigende anatomische Assoziationen erzeugen; in Wahrheit bezieht sich die Innigkeit des Kusses, ohne sich bei der Körperhülle aufzuhalten, allein auf das unkörperliche Innere des Körpers der Frau. Man kann gelegentlich sogar den Entstehungsprozeß 3 solcher metaphorischen und zugleich affektiven Formungen mitvollziehen. »Wissen Sie wohk, schreibt Klopstock an Meta in dem noch anakreontisch-scherzhaften Ton der fünfziger Jahre, »daß ich oft so närrisch bin, u Ihte Briefe küsse. [...] Ja, wenns nur der Brief allein wäre, den ich küßte, so wär es sehr romanhaft. Aber - ja aber! Eine gewisse kleine Hand, die schrieb; ein gewisses blaues Auge das zusah, als die Hand schrieb; ein gewisses unvergleichliches Herz (doch ein Herz kann man ja nicht küssen) ja, ... u was denn nun noch mehr? Ich muß hier nur aufhören, ich glaube sonst ich gebe thnen mehr als ein Mäulchen, wenn Sie auch noch so böse werden. $\ll^{38}$ Hicr ist die erotische Anzüglichkeit noch nicht im empfindsamen Fetischismus aufgegangen, und so bleibt auch metaphorisch präsent, daß der $\mathrm{Ku}$ aut das weibliche Herz uneigentlich ist und den Gedanken an andere Küsse und Körperpartien weckt. Andererseits wird schon die Filiation offengelegt, die dann die empfindsame Stilisierung bestimmt: der Kuß wandert vom Brief zur schreibenden Hand über das kontrollierende Auge zum Herzen, das die Hand lenkt, als der diskursiven Verbürgungsinstanz dieses Schreibens. Die libidinösen Besetzungen kehren also nicht oder bloß scheinbar vom Substitut zum Substituierten, von der Schrift zum Körper zurück, sondern schlagen an der Weggabelung zwischen Rokoko und Empfindsamkeit eine Richtung ein, die im Namen der $>$ Herzensschrift< umso tiefer in die Phantasmatik der Substitutionen hineinführt.

Bei Baggesen und Reinhold wird von einem Brief als »dieser neuesten Ergießung lhres Herzens in das meinige geschrieben werden. ${ }^{39} \mathrm{Im}$ skripturalen Fluß verlieren die Körper ihre materielle Undurchdringlichkeit. »Wie freue ich mich daraur «, so wieder Herder an Caroline, »in Ihren Briefen den Strom Ihres Herzens zu sehen, und ich weiß, es wird ein zutrauendes, offnes vergnügtes Herz seyn! « ${ }^{40}$ Der Kontext dieser indirekten Ermahnung zeigt, daB Herder seine Braut vor der »Unruhe« der Geschlechtlichkeit bewahxt sehen will. Ero-

37 Herders Briefwechsel (Anm. 31), II, 260 (30. 10. 1772).

38 Klopstock an Meta Moller, 29, 10. 1751. In: Klopstock (Anm, 11), Briefe II, S. 99.

39 Reinhold, 1.1791 In: Baggesen's Briefwechsel (Anm. 35) I, 8

40 Herder an Caroline, 23, 4. 1771, Briefwechsel (Anm. 31), I, 176. 
tische Erregung macht den Körper und damit den Weg zum Herzen undurchlässig. »Mein Geist soll Dich umschweben, er soll Dein Bette bewachen, aber nie, nie werde es mit einem Seufzer beunruhiget, das Bette, das Dich voraus immer heiter und Sorgenlos in seine Ruhe einschloß. «4 Caroline antwortet folgsam und keusch: »ich fliege mit meiner ganzen Heiterkeit und Fröhlichkeit in Thre Arme, um da auszuruhen «. ${ }^{22}$

Für diesen platonischen Verkehr sind Schriftlichkeit und die daraus resultierende wechselseitige Abwesenheit der Kommunikanten weniger Defizit als Bedingung. Ein jahrelanger Briefwechsel wie der zwischen Caroline Flachsland und Herder vertritt die Stelle der Tugendprobe, die eines der Hauptmotive der älteren Liebesromanzen und ihrer trivialisierten zeitgenössischen Ausläufer war. All das Umarmen, Küssen, Ergießen, Verschmelzen entspricht nur deshalb der empfindsamen Moralität, weil es sich über mediale Zwischenträger und in einer Verschiebung ereignet, die alle dabei stimulierten Affekte in einen höheren, spirituellen Aggregatzustand umsetzt. Das moralische Training der Alphabetisation besteht darin, sich an das strukturell bedingte Niveau der Vergeistigung anzupassen, sich die Negation des Körpers und die Affirmation seiner Abwesenheit - als Seele -- subjektiv zu übereignen. Sie steigert sich in dem $\mathrm{MaB}$, in dem der Schreiber sich vorbehaltlos, mit offenem Herzen und strömender Seele, den Transformationen der Verschriftlichung ïberläßt. Darin besteht der Gegensatz zu den diplomatischen billets d'amour der höfischen Kultur, die das Schreiben noch als Umweg in einem Bezugskreis rhetorischer Persuasion auffaßt und deshalb in der bürgerlichen Moralistik als liigenhafter Gegensatz zur Authentizität der Herzensschrift befehdet wird.43

So liegt die Funktion der Vergegenwärtigungsphantasien, die an den Schriftverkehr geknüpft sind, weniger darin, kommunikative Abwesenheit zu vermindern, als darin, sie semantisch zu stabilisieren. Was als Beziehungsideal intimer Seelenfreundschaft eingeführt wird, ist das Produkt dieses Effekts. Ein illustratives Beispiel bietet dafür - im Vorfeld der eigentlich empfindsamen Zirkel - das Wechselspiel zwischen imaginierter Nähe und bürgerlicher Distanz, das die modellbildende Korrespondenz des Gleim-Kreises vorführt. »So lange ich sie gelesen «, antwortet Gleim auf Briefe von Jacobi und Uz, "glaubte ich in Threr Gesellschaft zu seyn. «4 Aber diese Art von Gesellschaft hat wenig mit einem wirklichen Zusammensein gemein, das, so zärtlich die Beteiligten es herbeizusehnen scheinen, selten von Intimitätsangst und verstecktem Unbehagen frei bleibt. ${ }^{45} \mathrm{Im}$ Gegenteil: »Wahre Freundschaft«, so Ewald von Kleist,

41 Ebd.

42 Ebd., I, 180.

43 Ein Beispiel wäre der Brief in Schillers > Kabale und Liebeく. Zum Problem der Täuschung überhaupt, die alle Authentifizierungsstrategien unterläuft, vgl, neuerdings das aperçureiche Buch von Manfred Schneider: Liebe und Betrug. Die Sprachen des Verlangens. München Wien 1992.

44 Briefwechsel zwischen Gleim und $\mathrm{Uz}$. Hg. Carl Schüddekopf. Stuttgart Tübingen 1899. S. 386.

45 Darauf finden sich immer wieder Hinweise, vor allem in der Korrespondenz von Gleim mit Ramler und Ewald von Kleist. »ist auf keine sinnliche Empfindung gerichtet; die persönliche Unbekanntschaft hindert nichts. $\ll^{\sharp 6} »$ Doch seys $«$ versichert Caroline eine Generation später dem entfernten Herder, »wir sind vielleicht jetzt mehr beysammen als sichs solche köxperliche Menschen nicht träumen können. [...] ja mein Vortreflichster, es ist süße in der Entfernung zu lieben, und es erhebt die Seele zu einer Höhe und Stärke, die man vielleicht nicht im beständigen Umgang fühlte. $\ll^{47}$

Es sind die Körper, die im >Tod< des Buchstabens mit zu Tode kommen. Und es sind die Seelen, die durch den >Geist< der Schrift über alle Akzidenzien von Raum und Zeit hinweg schwerelos zueinanderfinden. »Ich bin«, versichert Siegwart, der Titelheld von Millers Roman, seiner in einem Kloster eingeschlossenen Geliebten, »jeden Augenblick bey dir; meine Seele ist stets ausser ihrem Körper, und umschwebt dich. «18 Schriftlichkeit bietet nicht nur erst die Möglichkeit zu solchen Mitteilungen; sie versachlicht das hier episodisch und erlebnishaft geschilderte Verlassen der Körperhülle zu einer kommunikativen Struktur. So wirkt sie über ihre Fetischfunktion hinaus, die den Körper der Kommunikanten ins Imaginäre rückt und zum Ziel objektlos-schwärmerischer Gefühlsproduktion macht, als ein transfiguratives Prinzip ${ }^{49}$, das ihn zuletzt überwindet. Deshalb kann Herder von einem Brief an Caroline sagen: »Es ist für mich recht die Stunde der Vergeistigung und einer kleinen Himmelfahrt, wenn ich zu thmen komme. «0 Und darum kann etwa Baggesen den Brief seines Freundes einen »Engel « nennen ${ }^{51}$, wie überhaupt diese Art von Briefver. kehr nach dem Modell himmlischer Kommunikation organisiert ist, in der sich geistige Wesen, von aller $\ddot{A} u ß e r l i c h k e i t$ befreit, in vollkommener Harmonie miteinander befinden.

Der Dichter, heißt eine neuerdings gern zitierte Passage bei Herder, "soll Empfindungen ausdrücken: - Empfindungen durch eine gemahlte Sprache in Büchern ist schwer, ja an sich unmöglich. Im Auge, im Antlitz, durch den Ton, durch die Zeichensprache des Körpers - so spricht die Empfindung eigentlich, und überläßt den todten Gedanken das Gebiet der todten Sprache. Nun, armer Dichter! und du sollst deine Empfindungen aufs Blatt mahlen, sie durch

46 Kleist an Uz, 19. 12. 1746. In: Ewald von Kleist's Werke. Hg. August Sauer. 3 Bde. Berlin 1880. Bd. 2. S. 64 .

47 Herders Briefwechsel (Anm. 31), I, 194f. (6. 5. 1771).

48 Johann Martin Miller: Siegwart. Eine Klostergeschichte. Faksimiledruck nach der Ausgabe von 1776. Stuttgart 1971. 2. Bde. Bd. 2, S. 991

49 In ähnlicher Bedeutung spricht Neumann vom »transfiguralen Prinzip literarischer Zeichenordnungen: Gerhard Neumann: >Lasst mich weinen ...< Die Schrift der Tränen in Goethes West-östlichem Divan. In: Oxford German Studies 15 (1984), S. $48-76$. Dort S. 56 .

50 Herders Briefwechsel (Anm. 31), II, 66 (21. 3. 1772).

51 Baggesen's Briefwechsel (Anm. 35), I, 96 (28. 9. 1791). 
einen Kanal schwarzen Safts hinströmen, du sollst schreiben, daß man es füht, und du sollst dem wahren Ausdrucke der Empfindung entsagen; du sollst nicht dein Papier mit Tränen benetzen, daß die Tinte zerfließt, du sollst deine ganze lebendige Seele in todte Buchstaben hinmahlen, und parliren, statt auszudrükken. $\ll^{52}$

Auf der Ebene der sinnlichen Existenz konstituiert Schrift ein System der Verschiebungen, Ungleichzeitigkeiten, des unaufholbaren Aufschubs; sie zerstört die Unmittelbarkeit persönlicher Interaktion. Andererseits aber besorgt sie durch den Durchgang vom Buchstaben zum Geist die Konversion jener ersten in eine sekundäre Präsenz, die gerade durch physische Abwesenheit bedingt und deren Modus das Imaginäre ist. Denn das 18. Jahrhundert ging von einer einfachen Definition der Einbildungskraft aus: als »Supplement der Sinne «3 ist sie das Organ für Abwesendes, und ihre Aufgabe besteht darin, das, was keine aktuale sinnliche Präsenz hat, der Seele gegenwärtig zu machen. Mit dem Autarkwerden von Schrift rücken die kommunikativen Beziehungen überhaupt in das Geltungsgebiet der Einbildungskraft. Semiotisch entsprich dem der durch Schrift bedingte Ausschluß natürlicher Zeichen. Nach den Poetiken des 18. Jahrhunderts, die den Primat der Dichtung über der Malerei behaupten, besteht das Privileg der alphabetischen Schrift gerade im arbiträren Charakter ihrer Zeichen, die nur als verschwindende Träger von Bewußtseinsge halten fungieren und sich deshalb zu rein intellektuellen Operationen eignen. ${ }^{5}$ Nur wo die Signifikanten keine sinnliche Verwandtschaft mit ihrem Gegenstand mehr besitzen, können die Seele und in ihrem Dienst die Imaginationskraft unbeeinträchtigt tätig sein. Phantasie setzt die Stillegung der Sinne voraus. ${ }^{55}$ So bildet sich auf́ der Rückseite medialer Vermittlung eine neue Art von Unmittelbarkeit : eine Koinzidenz der Gemuiter, die im Vorstellungsraum >hinter $<$ den Signifikanten und unter Abstoßung der Signifikanten entsteht.

Die schriftliche Botschaft ist insofern eher als die mündliche dazu geeignet, Zugang zur Innerlichkeit des Rezipienten zu finden. Zwar sind ihr die drei Wirkungen lautlicher Interaktion: physische Nähe, Reziprozität, Gleichzeitig. keit des Sprechens und Hörens, versagt. Dafür ist die Schriftkommunikation vom physischen Ursprung des Gesprochenen frei, sie kennt den Körper nur als

52 Johann Gottfried Herder: Über die neuere Deutsche Litteratur. Dritte Sammlung. In: Herders Sämmtliche Werke. Hg. Bernhard Suphan. 33 Bde. Berlin $1877 \mathrm{ff}$. Bd. 1, S. $394 f$.

53 Johann George Sulzer: Untersuchung über den Ursprung der angenehmen und unangenehmen Empfindungen. In: ders.: Vermischte philosophische Schriften. Leipzig 1773. Reprint Hildesheim New York 1974. S. 26.

54 Den Anfang machen hier offenbar die Schweizer Ästhetiker. Eine Stelle für viele: »Endlich enthält die Poesie einen besondern Vortheil daher, daß sie sich der blossen Worte bedienet; denn da dieses willkührliche Zeichen der Begriffe und Bilder sind, die sich alleine dem Verstande vernehmlich machen, kan sie dadurch ihre Bilder unmittelbar in das Gehirn anderer Menschen schildern [...] « (Johann Jacob Breitinger: Critische Dichtkunst. Faksimiledruck nach der Ausgabe 1740. 2 Bde. Stuttgart 1966. Bd. 1, S. 19f.)

55 Art. »Einbildungskraft«, in: Johann Georg Sulzer: Allgemeine Theorie der Schönen Künste. 2. Aufl. Leipzig 1792. Reprint Hildesheim 1967/70. Bd. 2. S. 11 f. einen Vorstellungsinhalt, während der kommunikative Vorgang selbst die Körper ohne Mühe gleichsam durchkreuzt und ausschließlich an die Seelen adressiert ist.

Auf dieser Stufe sind die Körper keine Realitäten mehr, die die Seelen trennen und von ihrer Transfiguration und Verschmelzung abhalten, sondern Seelenprodukte, hervorgebracht von einer Vorstellungskraft, die am Nullpunkt der Sinne, am Punkt der medialen Entwirklichung tätig zu werden beginnt. Unter den Bedingungen der Schrift sind Körper grundsätzlich >wiederkehrende< Körper. Die Schrift ist das Gitter, das sie verschwinden und wiederkehren läßt, die Gelenkstelle zwischen dem Realen und dem Imaginären. Der »tote Buchstabe« markiert die Durchgangsstelle von ihrer realen Mortifikation zu ihrer imaginären Wiedererstattung. Jenseits dieses Todesstadiums stellt sich ein sympathetischer Zusammenklang der Geister her, der dem Geltungsbereich mechanischer Gesetze nicht mehr angehört und seine Beschreibungsmittel in der neueren Physik immaterieller, alles Trennende penetrierender Ströme findet: in der Welt der Elektrizität und des Magnetismus, zweier Phänomene, deren paradigmatische Wirkung sich nicht nur auf das medizinische Menschenbild (wie im Fall des Mesmerismus), sondern auch auf die literarische Anthropologie erstreckt. ${ }^{56}$

Immer steht dabei die Schrift als Prinzip der Differenzerzengung zugleich im Zeichen eines Versprechens reiner, uneingeschränkter Gegenwart. Man findet dieses Doppelphantasma - Tötung und Erweckung, die den Tod vergessen< läßt und dem psychoanalytischen Begriff der Verdrängung analog arbeitet; scheinbare Transparenz der Signifikanten, die das Bezeichnete in Wahrheit vom mimem tisch postulierten Urbild weg in eine medial konstituierte Welt verschieben auch in anderen, im engeren Sinn ästhetischen Zusammenhängen. Ähnlich der Schrift fungiert der Marmor, in einem durchaus analogen Kontext des aufgeklärten Bildungsdenkens, als ein Kältemedium, das über die Etappe der Tödlichkeit hinweg sinnliches in imaginär reproduziertes $>$ Leben< übersetzt. Daß das Studium von Plastiken einem sinnlichen Buchstabieren ähnelt, gehört zu den Topoi der zeitgenössischen Kunstbeschreibung; umgekehrt hat auch das Lesen es mit einem kalten und harten Material zu tun, das sich in Lektüreakt erwärmt, belebt und verflüssigt. Im Briefwechsel zwischen Herder und Lavater wird dieser $\mathrm{Zu}$ sammenhang anläßlich von Herders Plastik-Schrift expliziert. Wie der Marmor nach Herders Worten im ästhetischen Genuß »sich beleben und zuletzt ganz verschwinden« sollte, so soll »das harte Buchstabiren zum harmonischen, fließenden Lesen « und damit zum Eintritt in die Welt des Lebens der Bedeutungen führen. ${ }^{57}$

56 Ein Beispiel: Christoph Martin Wieland: Sympathien. In: Ders.: Sämmtliche Werke. Bd. 13. Leipzig 1798. Neudruck Hamburg 1984. S. 127-208. Bes. S. 133f.

57 Lavater hatte geschrieben: »Ich glaub', es ist der harte Maxmor an der Bildsäule, die ich nun mit der geistigsten Fingerspitze betaste, und der nicht Fleisch werden will.« Darauf Herder im Juli 1779: $\gg$ Daß Dich die >Plastik< gedrückt hat, glaub' ich gern [...]. Der Marmor sollte sich beleben und zuletzt ganz verschwinden (si dis placet); denn sieh einmal aufs zweite Blatt, was noch folgen sollte, und wovon die >Plastik< nur das erste, härteste, dürttigste Element ist. Element indeB ist, wie das harte Buchstabiren zum harmonischen, fließenden Lesen. Der liest freilich schlecht, der im Lesen buchstabirt, noch schlechter aber, der nie oder in schweren Fällen nicht buchstabiren gelernt. So mit Plastik und dem Gefühl des Schönen.« (Aus Herders Nachlaß (Anm. 34), II, 181 bzw. 183.) 
Die Patenschaft Pygmalions erstreckt sich so auch auf das Lesen, das aufhört, rhetorische Repetition zu sein, und zum Verstehen in dem emphatischen Sinn des 18. Jahrhunderts wird. Auch hier ist eine Affektivität am Werk, die wie im Fall Pygmalions den Körper, der nur Körper und kein Zeichen ist, verschmäht und sich Erfüllung allein im Versprechen der Verkörperung des Zeichens, in einer Erotisicrung des Mediums selbst erträumt: eine Ästhetik der Verfehlung, die sich den Anschein der Erfüllung gibt. Zu methodischer Relevanz kommt das pygmaliontische Prinzip der Zeichenbelebung in der Hermeneutik, die in ihrer Neukonstitution um 1800 dicht an den Bildapparat der Alphabetisationskampagne im Aufklärungsjahrhundert anschließt. »Jedes Buch«, heißt es bei Bergk, einem an Kant geschulten Verfasser von Denk- und Lesepropädeutiken, »ist eine todte Masse, die bloß dadurch belebt wird, daß wir mit unserm Verstand selbstthätig bei der Lectüre desselben verfahren. Wir müssen daher dasjenige aus uns selbst hervorlangen, was dieses Todtengerippe nicht enthält, und wir müssen ihm durch Selbstthätigkeit Geist einhauchen, wenn es kraftlos zu Boden sinken will. $\aleph^{58}$ Das ist das rezeptive Gegenstiick zu Herders Klage, daß man die Empfindung nicht unmittelbar an den Leser überschreiben kann. Anders als nach dem rhetorischen Modell der Rede ist unter den Bedingungen emergenter Schriftlichkeit die Beziehung zwischen Autor und Leser unterbrochen. Auf der einen Seite gibt es das geistige Leben des Autors, das er in Signifikanten deponiert; auf der anderen Seite die hermeneutische Selbsttätigkeit des Lesers, die durch den Tod der Schrift zugleich gesichert und heraufgerufen ist. Zwischen beiden steht die Materialität des Textes, die wie die Natur bei Kant bedeutungsleer ist. Gegenïber dem rhetorischen Modell direkter affektiver Übertragung liegt das Neue der Lesekunst um 1800 darin, gerade die Kontingenz zwischen den Kommunikanten, die mortifizierende Wirkung der Zeichen, über die sie sich verständigen, hervorzuheben. Nichts soll an dem Nullstadium toter Materialität vorbeiführen und die rezeptive Freiheit des Lesers infragestellen. Die Durchsetzung einer vollen Arbitrarität der Zeichen bildet erst die semiotische Basis dafür, eine Vielzahl autonom gesetzter, subjektiver Sinnwelten zu proklamieren, wie es die Hermeneutik um 1800 im Gefolge des Idealismus tut.

Wenn aber verstehende Lektüre glückt, hat Geist Geist induziert, und das Todesstadium der Signifikanten verschwindet aus dem BewuBtsein. Bergk äußert sich nicht zu den Einfühlungsprozeduren, die seit Schleiermacher für die Hermeneutik maßgeblich sind. Aber auch bei ihm treten über die Differenz konstitution der Schrift hinweg Autor und Leser in Kontaki und lassen zuletzt aus dem doppelten Monolog auf einen unsichtbaren Partner zu eine schwerelose Konversation der Geister werden. »Der Leser«, so Bergk, »unterhält mit dem Verfasser eines Buches ein Gespräch, worin jeder seine Gedanken gegen die Gedanken des Andern austauscht, jeder dem Andern nachhilft, und wo Einer durch den Andern belebt, erbauet und belehrt wird. «5\%

58 Johann Adam Bergk: Die Kunst, Bücher zu lesen. Nebst Bemerkungen über Schriften und Schriftsteller. Jena 1799. Reprint München Berlin 1971. S. 184. 59 Ebd., 174.
VI.

Man kann den medialen Mechanismus, der die intellektuelle Subjektkonstitution im 18. Jahrhundert prägt, auch in Begriffen der Fragmentierung und der Ganzheit beschreiben. Denn die Identitätsbildungsprogramme, die mit dem Programm der Alphabetisation zusammengehen, greifen nur, insoweit sie die gewissermaßen voralphabetischen Identitäten, mit denen sie es anfangs zu tun haben, zerstören. Sie statuieren einen Mangel, dessen Behebung sie dann in einer Arbeit unendlicher Perfektibilisierung in Aussicht stellen. Die Moralischen Wochenschriften und ähnliche Organe, die zugleich der Verbreitung des Schriftgebrauchs und der bürgerlichen Moralvorstellungen dienen, müssen auf beiden Ebenen ihr Publikum erst rekrutieren: eine Leserschaft, die alphabetischer Indoktrination und auf diesem Weg moralischer Belehrung zugänglich ist und schließlich in deren Abhängigkeit gerät. Der Hauptfeind der Tugendlehre ist nicht so sehr das Laster als die Selbstgenügsamkeit, und zwar sowohl in bezug auf sittliche Lebensfïhrung im engeren Sintı als auch auf $A n s c h l u B$ an den Bildungsdiskurs überhaupt.

Kommunikationssysteme verhängen Selbstbefriedigungsverbote. ${ }^{\circ 0}$ Sie unterbinden Kurzschlüsse unterhalb der Systemebene. Luhmann nennt als eine solche Kurzschlußhandlung, bezogen auf den Code der Liebe, die Onanie. ${ }^{61}$ In der Tat erklärt sich die Erbitterung, mit der die Antimasturbationskampagne im 18. Jahrhundert gefuhrt wurde - mit ihrem Höhepunkt in der empfindsamen Periode - weniger aus einem Ressentiment gegen verschwenderische Lust als solche mit den bekannten zerstörerischen Folgen als aus dem Zorn über die Selbstabschließung des Onanisten, der sich gegenüber jedem pädagogischen und sozialen Impetus immun macht, dem allgemeinen Bildungswerk entzieht und insofern den Begriff des Menschen als eines perfektiblen Wesens überhaupt verfehlt. Deshalb muß das Schicksal solcher Delinquenten in Bildern der Stagnation und Infantilisierung, schließlich des physischen und geistigen Niedergangs geschildert werden. Nichts ist gefährlicher für die Moral als ein Narzißmus, der keinen Mangel fühlt. Die Lesepropädeutiken, die sich zumal der Zurichtung der Frau verschreiben, haben eine erklärtermaßen antinarzißtische Tendenz. Auch hier entwerfen sie ein Gegenbild zur Leserin, in einer Antithetik, die dem Gegensatz zwischen philantropischem Zögling und Onanisten analog ist: das der koketten Frau, die ihre Zeit damit verschwendet, sich im Spiegel anzusehen. Martens hat auf die Verbreitung dieses Antimodells im Umkreis der Moralischen Wochenschriften hingewiesen ${ }^{62}$; vermutlich über den Pictismus vermittelt, ist es im gesamten aufklärerischen Moralschriftum mit seiner StoBrichtung gegen weibliche Reizentfaltung, Eitelkeit und Verstellung auffindbar.

60 Niklas Luhmann: Einführende Benerkungen zu einer Theorie symbolisch generalisierter Kommunikationsmedien. In: Ders.: Soziologische Aufklärung 2. Aufsätze zux Theorie der Gesellschaft. Opladen 1975. S. 170-92. Dort S. 181.

61 Ebd.

62 Wolfgang Martens: Die Botschaft der Tugend. Die Aufklärung im Spiegel der deutschen Moralischen Wochenschriften. Stuttgart 1968. S. 532. 
Die Aufgabe der durch Lesen vermittelbaren Bildung besteht darin, die Selbstbespiegelung der koketten Frau zu unterbrechen. Sie soll den Spiegel mit dem Buch vertauschen und sich dadurch kommunikativ anschlußfähig machen, das heißt den Intruisionen männlicher Moralschriftsteller öffnen. Die Alphabetisationskampagne setzt damit ein, die Idee einer im Spiegel sichtbar werdenden körperlichen Ganzheit zu destruieren: sei es, daß unter Rückgriff auf barocke Drastik die Spiegelbetrachterin die Pocken bekommt und sich dadurch von ihrer Eitelkeit weg zut Tugend führen läßt, sei es, daß man sie mit Anschluß an das weite Feld der Marmorfrauen-Motivik seinem leblosen Venus $=$ Bilde $\ll$ gleichstellt ${ }^{63}$ oder mit den Metaphern der Marionette und der Puppe in Verbindung bringt, wie sie im Zeitalter des ausgehenden Cartesianismus für das nur Körperliche und Mechanische geläufig waren.

Doch diese Destruktion äußerer Makellosigkeit wird sogleich von dem Versprechen einer inneren Vervollständigung abgelöst. »So eifersüchtig bin ich wol nicht, daß ich Ihnen alle Vertraulichkeit mit ihrem Spiegel verbiete«, heißt es scheinbar konziliant in Leonhard Meisters Sittenlehre mit Wendung an dic prospektive Leserin (dex Autorfiktion nach die Braut):

»fürnemlich aber erwarte ich, daß Sie mit sich selber vertraut seyen. Wenn es für Sie interessant ist, zu untersuchen, wie sich auf ihren Wangen die Lilien mit den Rosen, sollte die Untersuchung für Sie weniger interessant seyn, wie sich in ihrer Seele Begriffe mit Begriffen, Empfindungen mit Empfindungen verweben? Wie eine Leidenschaft, ein Gedanke aus dem andern entstehet, und wie sich ihe Aeste und Zweige in einander verlieren? Hier ist es, wo ich Ihnen aus Mangel eines geprüften Freundes oder einer vertrauten Gespielin solche Schriften empfehle, die uns mit der Natur und dem Ursprung der Gemüthsbewegungen, mit ihrer Vermischung und ihren gegenseitigen Verhältnissen, die uns mit uns selber, mit unsern Tugenden und mit unsern Fehlern bekannt machen, $\ll^{64}$

So wird die Selbstbespiegelung der Frau nicht einfach nur zerstört, sondern erweitert: um die Vermittlung durch ein Schrifttum, hinter dem in erster Linie schriftstellernde Männer stehen. Die naive narzißtische Ganzheit wird ihr verdorben, aber den sichtbar gewordenen Mangel kann die Frau beheben, wenn sie sich einer diskursiven Führung anvertraut. Und doch wird sich die Ganzheit niemals wieder schließen. Aller Topik zum Trotz ist weibliche Tugend niemals vollkommen; sie besteht vielmehr darin, sich dem Zwang zu beständiger Vervollkommnung zu unterstellen. Wahre Tugend existiert nur in Form einer unaufhörlichen Bewährung. Dieser Zwang der Verzeitlichung garantiert den dauerhaften Anschluß der tugendwillig gemachten Frau an die medialen Instanzen der Moralität. Wie das Schuldprinzip der Kirche ihre Gläubigen sicherte, sichert das Tugendprinzip der Aufklärungspublizistik eine ständiger Belehrung bedürftige Leserschaft. Wer einmal an den Diskurs angeschlossen ist, kann sich nicht wieder in Ubereinstimmung mit sich selber bringen; er bleibt in

63 Beide Beispiele bei Martens, 534 .

64 Leonard Meister: Sittenlehre der Liebe und Ehe, nebst einer Beylage über die helvetische Galanterie. Winterthur ${ }^{2} 1785$. S. 10 f. einer Maschinerie des Mangels gefangen. Insofern ist die Leserin von Sittenschriften enger verwandt mit der Romansüchtigen, die sich imaginäre Frfiul lung erhofft, als es die moralistischen Antithese, die sie gegeneinander ausspielt, vermuten ließe. Beide erwarten ihre Vervollständigung von der gleichen Instanz, die sie fragmentiert hat. Beide folgen einem. Ganzheitsversprechen, das medial codiert ist und sich nur um den Preis der Medialisierung selbst erfitllt.

VII.

Wenn es richtig ist, daß die Alphabetisation nicht einfach einen neutraten Boden für Bildungs- und Erkenntnisprogramme abgibt, sondern schon ihrex Funktionsweise nach, als kommunikatives Apriori, den ProzeB der Subjektformung bedingt, ja wenn subjektive Identität sich iberhaupt erst im Spiegel der Beständigkeit der Schrift als pädagogisch-autobiographische Konstruktion herstellt, dann hat das Auswirkungen auch auf den Begriff und die Methodik der literarischen Anthropologie. Sie wird ihre Inhalte nicht einfach aus den schriftlichen Quellen beziehen können - was dem alten Schema entspräche, daß Li teratur, in welcher hermeneutisch zu berücksichtigenden Vermittlung auch immer, Ausdruck und Wiedergabe sozialhistorischer Realitäten ist, daß sie etwas abbildet, was außerhalb von ihr liegt -., sondern muß den Faktor Schrift selbst in Rechnung stellen. Die für die Literatur relevanteste sozialhistorische Realität des 18. Jahrhunderts scheint in der simplen und deshalb leicht zu übersehenden Tatsache zu bestehen, daß die für die bürgerliche Gesellschaft grund legenden Affektmodellierungen und Subjektdefinitionen sich im Medium der Schriftlichkeit vollziehen, daß sie Elemente eines erstmals zu voller Ausprägung gelangten neuartigen Kommunikationssystems sind. Die Entstehung der Industriegesellschaft fällt mit den Anfängen der Mediengesellschaft zusammen, und folglich ist auch die Literatur, hier im weitesten Sinn verstanden als Summe aller geschriebenen Texte, nicht allein Spiegel der sozialen Prozesse, sondern einer ihrer maßgeblichen Operatoren.

Es wurde gezeigt, daß die aufgeklärte Schriftkultur auf der Basis der Abschneidung der Körper neue Imaginationen der Präsenz, individueller und kommunikativer Vervollständigung entstehen läßt. Es wurde weiter gezeigt, daß dem ein zweistufiges phantasmatisches System entspricht: auf eine Phase der Beraubung, in der >Körper $<$ und $>$ Leben $<$ durch Transfer in arbiträre Signifikanten abgetötet werden, folgt eine Phase der Rekompensation, in der das Leben als Bedeutung wiederaufersteht. In dieser Wiederherstellung von Ganzheit rückt der privative Prozeß, der ihr vorausgeht, in ein diskursives Unbewußtsein; er wird namenlos. So usurpiert das Medium die Erinnenung an das, was vorher war, und läßt es als sein virtuelles Produkt erscheinen. Die literarisch induzierte Erfahrung gibt sich als voller aus, als es eine nichtalphabetisierte wäre. In den empfindsamen Romanen wird das zu einem trivialen Schema: Klopstock-Leser als Prototypen enthusiastischer Leserschaft lieben tiefer, 
dringen im Geist der Seelenliebe zu einem emphatisch-ganzheitlichen Menschsein vor, während die, die den Schritt der Sublimierung nicht volziehen, als partikular erscheinen und von Dekompositionen welcher Art auch immer bedroht sind. Liebe und Literatur verschränken sich hier in einer Weise, die es unmöglich macht, sie entlang einer supponierten Grenze zwischen lebensweltlichem Ursprung und dessen Reproduktion zu sondern. Die Empfindsamkeit stellt insofern eine entscheidende Etappe in dem doppelten Prozeß der Medialisierung der Erotik und der Erotisierung der Medien ${ }^{65}$ dar, der von da an die Strukturen des gesellschaftlichen Imaginären beherrscht. Die $»$ Rehabilitation der Sinnlichkeit « ${ }^{65}$, die sich im 18. Jahrhundert in Lossagung von den rationalistischen Restriktionen zugetragen haben soll, ist medienhistorisch nur ein Effekt ihrer Codierung. Sie spiegelt keine Lockerung der gesellschaftlichen Affektökonomic wider, die sich angesichts der Kontinuität zwischen Aufklärungsmoralistik und Viktorianismus auch kaum denken läßt, sondern markiert den Beginn des Prozesses medialer Monopolisierung der Lust, der in der Industrie des Unbewußten heute mündet. ${ }^{77}$ Wie der empfindsame Transfer von Literatur in Leben oder die klassizistische Konjunktion von Weiblichkeit und Marmor - signifikant in Herders Begierde, den »Marmor« zu »fühlen«, die das Seitenstiick zum Platonismus seiner Brautbriefe bildet6s - sinnfällig machen, wird die sinnliche Lust im Prozeß ihrer scheinbaren Freigabe erst recht an ästhetische Repräsentanzen gefesselt. Das schränkt auch den Stellenwert der anthropologischen Konzepte yon bildsamer Ganzheit ein, die den ästhetischen Entwurf des Menschen komplementieren. Die Diskurse, die sich im 18. Jahrhundert um das Wesen des Menschen herausbilden, sind auf dieses Signifikat nicht abbildend-inhaltich, sondern performativ bezogen.

65 Ähnlich Müller (Anm. 12), S. 284.

66 Vgl. Panajotis Kondylis: Die Aufklärung im Rahmen des neuzeitlichen Rationalismus. Stuttgart 1981. S. $42 \mathrm{ff}$.

67 Fredric Jameson: Postmodernism, or The Cultural Logic of Late Capitalism. In: New Left Review 146 (1984). S. 53-92. Dort S. 78 u. passim.

68 Herders Programm einer visuellen Simulation von Taktilität, den »gleichsam unter der fühlenden Hand belebten Marmor « »zu sehen, als ob man tastete und griffe«, wird vielleicht am deutlichsten in seinem $>$ Vierten kritischen Wäldchen $<$. Herder (Anm. 52), Bd. 4, S. 66 bzw. 65. 